\title{
Health Policy Perspective: Medicaid and State Politics Beyond COVID
}

\author{
Jane M. Zhu, MD, MPP 1,2 (1), David Grande, MD, MPA ${ }^{2,3}$, David K. Jones, $P h D^{4}$, and \\ Renuka Tipirneni, MD, MSc ${ }^{5,6}$
}

\begin{abstract}
'Division of General Internal Medicine and Center for Health Systems Effectiveness, Oregon Health and Science University, OR, Portland, USA; ${ }^{2}$ Leonard Davis Institute of Health Economics, University of Pennsylvania, Philadelphia, PA, USA; ${ }^{3}$ Division of General Internal Medicine, University of Pennsylvania, Philadelphia, PA, USA; ${ }^{4}$ Department of Health Law, Policy, and Management, Boston University School of Public Health, Boston, MA,

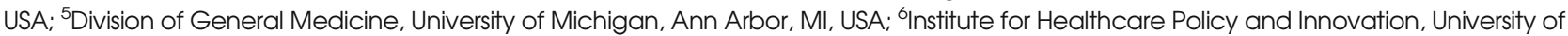
Michigan, Ann Arbor, MI, USA.
\end{abstract}

The COVID-19 pandemic is poised to drastically alter the Medicaid program. While state Medicaid programs are currently expanding coverage policies and enrollment to address acute public health needs, states will soon face significant budget shortfalls. These impending changes may renew partisan debates about restrictive policies like work requirements, which generally require beneficiaries to verify their participation in certain activities-such as employment, job search, or training programs-in order to receive or retain coverage. We argue that restrictive Medicaid policies are driven, to a great extent, by political party affiliation, highlighting the outsized role of partisanship in Medicaid policy adoption. To combat these dynamics, additional efforts are needed to improve community-informed decision-making, strengthen evaluation approaches to tie evidence to policymaking, and boost participation in and understanding of the political processes that affect policy change.

$\mathrm{J}$ Gen Intern Med 35(10):3040-2

DOI: $10.1007 / \mathrm{s} 11606-020-06117-1$

(c) Society of General Internal Medicine 2020

$\mathrm{T}$ he COVID-19 pandemic is poised to drastically alter the landscape - and politics — of the Medicaid program. As the nation's social safety net, Medicaid is expected to absorb many of the millions of newly unemployed, with states projecting higher spending and enrollment continuing into 2021 as a result. ${ }^{1}$ However, despite a temporary increase in Medicaid's federal match rate to provide fiscal relief during the pandemic, ${ }^{2}$ states may soon face significant budget shortfalls and spending cuts even as demand for services grows. These economic realities and uncertainties may renew partisan politics around Medicaid, particularly around policies that restrict eligibility, increase cost-sharing, or limit enrollment.

Received May 4, 2020

Accepted August 5, 2020

Published online August 19, 2020
Many of these policies have been proposed previously via Section 1115 waivers, which provides the authority for states to diverge from federal Medicaid guidelines and pilot different approaches in coverage and care delivery. Nowhere, perhaps, has this political litmus test been more pronounced than with state-level adoption and implementation of Medicaid work requirements, which the Centers for Medicare and Medicaid Services (CMS) first approved in January 2018. Work requirements generally require beneficiaries to verify their participation in certain activities - such as employment, job search, or training programs - or substantiate an exemption, in order to receive or retain coverage. Studies show that work requirement policies are associated with declining coverage, unchanged employment rates, ${ }^{3}$ and increased administrative costs. ${ }^{4}$ While momentum for work requirements has stalled in response to ongoing legal concerns about coverage losses, ${ }^{5}$ and amidst heightened needs during the COVID pandemic, there are hints that such policies could be revived: in July 2020, for instance, the state of Arkansas filed a petition to the Supreme Court to reinstate Medicaid work requirements, ${ }^{6}$ which had been struck down both in federal District and Appeals courts.

These developments are a continuation of long-standing state-level partisanship around Medicaid policies. Under the Affordable Care Act (ACA), for instance, there has been wide variation in Medicaid program expansion along partisan lines in Republican- and Democrat-controlled states. ${ }^{7}$ As of August 2020, twelve states have still not expanded Medicaid, often due to state legislature and/or gubernatorial opposition. In a similar vein, several Republican-led state legislatures in the 2018-2019 legislative sessions tied work requirements to Medicaid expansion (e.g., VA), as well as in separate proposals in non-expansion Medicaid programs (e.g., SC, WI). ${ }^{8}$ Moreover, political decisions made by state legislatures often have been at odds with public preferences, representing institutional barriers to voter-led efforts. To date, for example, six states - ME, NE, ID, UT, OK, and MO - have successfully adopted Medicaid expansion through ballot initiatives. ${ }^{9}$ Both in Idaho and Utah, however, after voters passed ballot initiatives for full Medicaid expansion, Republican-controlled 
legislatures revised these initiatives to include work requirements. $^{7}$

These circumstances beg the question: to what extent are restrictive Medicaid policies driven by partisanship, rather than by evidence?

A great deal, it turns out — at least as suggested by a large body of work in political science. While Medicaid is highly popular with voters from both political parties, ${ }^{10}$ studies show that implementation of the ACA, and particularly Medicaid expansion, was heavily influenced by legislators' political ideologies as well as by business and lobbying interests. ${ }^{7}$ Across different studies, and using various measures of partisanship, Democratic control at the state government level had a strong positive influence on the movement towards Medicaid expansion, and Republican control had a strong negative influence. ${ }^{11-13}$

Our own work supports these findings. We linked districtlevel demographic and socioeconomic characteristics from the 2017 American Community Survey (ACS) to a survey conducted in late 2017, representing 49 states and the District of Columbia that assessed state legislators' support for work requirements, among other Medicaid waiver proposals. ${ }^{14} \mathrm{We}$ found that support for Medicaid work requirements among state legislators was more strongly associated with political party affiliation (i.e., Republican vs. Democrat) than with any other legislator or district-level characteristics. These findings highlight the extent to which support for Medicaid restrictions are lifted by political currents as opposed to empirical evidence or community needs.

Taken together, this evidence reflects a growing ideological divide about Medicaid's purpose and its place in the health care system. However, although partisanship may be a constraint, it is not the only factor that influences state-level decisions on Medicaid program policies. Research suggests that prior policies towards low-income people and the uninsured also influence the direction of state-level decision-making in Medicaid, ${ }^{12,13}$ because policy legacies tend to set the context and range of politically feasible options for lawmakers. Likewise, state-level administrative capacity appears to influence the adoption, design, and support of Medicaid policy changes. ${ }^{13}$

These findings bear a number of important implications as we consider the program's future. Due to COVID-related coverage losses from employer-sponsored insurance, state Medicaid programs are expected to absorb up to 12 million new enrollees, which will likely require expanded operational and policy capacity across Medicaid agencies. Given that Medicaid is a central tool in responding to our current national public health emergency, states also have pursued waiver flexibilities around expanding telehealth coverage and access; covering testing for uninsured individuals; modifying eligibility requirements; adjusting existing benefits; and eliminating cost-sharing charges. These changes, however temporary, may have lasting effects on the types of policies that Medicaid adopts and that lawmakers will support politically in the long run.
Yet for many states, budget shortfalls will require significant cuts to Medicaid, leading to new challenges as an unprecedented number of individuals rely on public programs for coverage. In NV, for instance, state lawmakers recently convened a special session to address a budget shortfall for the fiscal year 2021, preparing to cut millions from Medicaid, reducing reimbursement rates, and eliminating a number of services. ${ }^{15}$ As such, a number of additional recommendations may help to counteract policy adoption based strictly on partisan inclinations.

First, there has been longstanding concern that Medicaid policymaking may lack meaningful engagement with the populations served by the program. To mitigate the adverse consequences of restrictive Medicaid policies, lawmakers ought to improve community-informed decision-making and better incorporate the needs and priorities of enrollees. Additional effort is needed to solicit the voices of low-income, vulnerable individuals to ensure that impending program changes do not systematically disadvantage specific groups.

One possible avenue is to strengthen federal and state requirements for Medicaid 1115 waiver comment periods, which currently allow the public to provide feedback about proposed modifications to state Medicaid policy. An analysis of Medicaid 1115 comment letters submitted to federal regulators found that a majority of comment letters were from Medicaid-eligible individuals, signaling potential for robust public engagement around agenda-setting and program design. ${ }^{16}$ Another approach would be to enhance outreach to Medicaid populations through listening tours, town halls, and Medicaid member advisory councils, as MI, VA, and other states are implementing. These efforts may improve public knowledge about proposed Medicaid policies, increase public engagement, and build a constituency among low-income and vulnerable populations served by Medicaid, all of which could potentially strengthen health care quality and outcomes for beneficiaries over time.

Second, there is an urgent need for rigorous Medicaid waiver evaluations, as the Administration's current emphasis on state flexibility encourages large variations in Medicaid programs driven by political compositions at the state level. In this context, more robust evaluation approaches - including randomized controlled trials and quasi-experimental observational studies - are necessary to tie evidence to future Medicaid policy. There is also a need to place greater emphasis on assessments of administrative costs and burden, both to states and to individual enrollees. Explicit guidance and state tools, released by CMS in March 2019, are a positive first step in facilitating more standardized evaluations that would yield useful lessons for program implementation across states and populations. This evidence should be targeted not only to federal policymakers but also to the public and to state lawmakers. Building a strong evidence base may help to support greater evaluation, monitoring, and accountability mechanisms to overcome partisan messaging on specific policies. 
Finally, understanding the future of Medicaid programs requires closer attention to the political mechanisms that affect policy design and adoption. Recent research by Philip Rocco and colleagues suggest that robust electoral competition may be a critical catalyst of states' implementation of Medicaid expansion under the ACA. ${ }^{7}$ Indeed, public opinion may influence Medicaid policy adoption more effectively when there are competitive elections and staunch voter pressure on legislatures. Greater attention to the political determinants of health is critical as partisanship increasingly drives health care policy and decision-making.

The COVID pandemic represents a critical juncture, both in Medicaid's role in public health and health care delivery in this country and also in the public's evolving perception of the program. Greater attention to incorporating community voices and evaluation rigor, and to addressing the political determinants of health, is needed to help ensure sound policies as the program provides care to a growing number of vulnerable Americans.

Acknowledgements: The authors thank Michael Fichman and Janet Weiner for their insights and expertise on prior related work.

Corresponding Author: Jane M. Zhu, MD, MPP; Division of General Internal Medicine and Center for Health Systems Effectiveness, Oregon Health and Science University, OR, Portland, USA (e-mail: zhujan@ohsu.edu).

Compliance with Ethical Standards:

Conflict of Interest: The authors have nothing to disclose.

\section{REFERENCES}

1. Early Look at Medicaid Spending and Enrollment Trends Amid COVID19. Kaiser Family Foundation. 2020. Available from: https://www.kff. org/coronavirus-covid-19/issue-brief/early-look-at-medicaid-spendingand-enrollment-trends-amid-covid-19/. Accessed 25 Jun 2020.

2. Key Questions About the New Increase in Federal Medicaid Matching Funds for COVID-19. Kaiser Family Foundation. Available from:https:// www.kff.org/coronavirus-covid-19/issue-brief/key-questions-about-the- new-increase-in-federal-medicaid-matching-funds-for-covid-19/2020. Accessed 21 Jul 2020

3. Sommers BD, Goldman AL, Blendon RJ, Orav EJ, Epstein AM. Medicaid Work Requirements - Results from the First Year in Arkansas. New England Journal of Medicine 2019;381(11):1073-82.

4. US Government Accountability Office. Medicaid Demonstrations: Actions Needed to Address Weaknesses in Oversight of Costs to Administer Work Requirements 2019. Available from:https://www.gao.gov/products/ GAO-20-149. Accessed 10 May 2020; (GAO-20-149).

5. More States Reconsidering Medicaid Work Requirements. Center on Budget and Policy Priorities. 2020. Available from: https://www.cbpp. $\mathrm{org} / \mathrm{blog} / \mathrm{more}$-states-reconsidering-medicaid-work-requirements. Accessed 31 May 2020.

6. Supreme Court of the United States. Available from: https://www. supremecourt.gov/search.aspx?filename=/docket/docketfiles/html/ public/20-38.html. Accessed 21 Jul 2020.

7. Rocco P, Keller AC, Kelly AS. State Politics And The Uneven Fate Of Medicaid Expansion. Health Affairs 2020;39(3):494-501.

8. Cardwell A. Learn the Latest about State Efforts to Implement Medicaid Work Requirements. The National Academy for State Health Policy. Available from: https://nashp.org/learn-the-latest-about-stateefforts-to-implement-medicaid-work-requirements/. Accesssed 2 Apr 2020.

9. Medicaid Expansion Across the Country: A Check-In on Recent Ballot Initiatives. The Commonwealth Fund. Available from: https://www. commonwealthfund.org/blog/2019/medicaid-expansion-across-country-check-recent-ballot-initiatives. Accessed 31 Mar 2020.

10. Iglehart JK, Sommers BD. Medicaid at $50-$ From Welfare Program to Nation's Largest Health Insurer. New England Journal of Medicine 2015;372(22):2152-9.

11. Grant R. The Triumph of Politics Over Public Health: States Opting Out of Medicaid Expansion. Am J Public Health 2013;104(2):203-5.

12. Lanford D, Guadagno J. Implementing ObamaCare: The Politics of Medicaid Expansion under the Affordable Care Act of 2010. Sociological Perspectives 2016;59(3):619-39.

13. Jacobs LR, Callaghan T. Why States Expand Medicaid: Party, Resources, and History. J Health Polit Policy Law 2013;38(5):1023-50.

14. Zhu JM, Chhabra M, Grande D. Concise Research Report: The Future of Medicaid: State Legislator Views on Policy Waivers. J Gen Intern Med 2018;33(7):999-1001.

15. Girnus AC. Nevada Lawmakers Consider Slashing Millions in Medicaid Services. Nevada Current. 2020. Available from: https://www. nevadacurrent.com/2020/07/09/nevada-lawmakers-consider-slashingmillions-in-medicaid-services/. Accessed 21 Jul 2020.

16. Jarlenski M, Rocco P, Tipirneni R, Kennedy AJ, Gunturi N, Donohue J. Shaping Health Policy for Low-Income Populations: An Assessment of Public Comments in a New Medicaid Waiver Process. J Health Polit Policy Law 2017;42(6): 1039-64.

Publisher's Note: Springer Nature remains neutral with regard to jurisdictional claims in published maps and institutional affiliations. 